\title{
A community treatment service for sex offenders
}

\author{
An account at two years
}

\author{
Eric F. Mendelson, Consultant Forensic Psychiatrist, Ravenswood House, Knowle \\ Hospital, Fareham, Hants; Michael QuinN Senior Forensic Social Worker; SuE \\ DutTon, Senior Forensic Social Worker; and Kishore SEEwONARAIN, Senior Registrar \\ in Forensic Psychiatry, The Edenfield Centre, Prestwich Hospital, Manchester
}

If you have been referred a sex offender recently, you will probably still be conscious of how difficult it is on an individual basis to provide a comprehensive treatment approach. Indeed, in our area, as in nearly all areas, there has been little therapeutic help available for sex offenders outside the special hospital system, and certainly little for those in the community.

We were aware that others, mainly interested probation officers ${ }^{1,2,3}$, had run groups in their local areas. But in the absence of formal treatment packages readily available to anyone who felt they needed help, regardless of whether they were on probation or parole, and moreover any work to evaluate the benefits or hazards of such a scheme, we were keen to develop an approach that could, should it be successful, be easily adopted by others.

Only one of us (EM) had had any significant experience in treating sexual deviants, but it was hoped that as the programme developed the basic skills could easily be acquired by the others, and in any case we would all have to learn the particular therapeutic needs of this scheme. Indeed, this pioneering spirit of enthusiasm proved a powerful motivating force for us all!

\section{Situation and staffing}

We were fortunate to be offered the use of a staff room in a probation office in the centre of Manchester in which to hold the groups. It was felt important to have at least one female therapist. Many members would have problems relating to women and would be anxious both about talking to, and revealing their feelings to, adults of the opposite sex. A female would also be more effective in enhancing the value of role play exercises and contributing a feminine view to discussions on sexual and dominance issues. Apart from the psychiatrist being the instigator of this project, it was felt by all that a medical member was an essential ingredient of the service. Psychiatric expertise is necessary to monitor cases, to liaise with other doctors, to arrange or provide other treatments and accept legal responsibility. Moreover, not only would the doctor give the project instant credibility in the eyes of lay people, but the courts seem to be more assured by this umbrella of traditional respectability. The other therapists were psychiatric social workers based in the local regional forensic unit. Their professional background facilitated close links with social services and they were able to undertake much of the work of assessments and follow-ups, including the research to evaluate the project.

\section{Early hurdles}

An unexpected complication in starting the group nearly dashed our tentative confidence. Bringing together so many inadequate and guilt-ridden men led to the powerful collective forces of group-denial. These forces reached crescendo in the sessions spent discussing the potential impact on their victims and in attributing the full responsibility to the perpetrators as adults. Each rallied to the support of the other, confirming how they were virtually seduced by their victims, who were far from sexually naive and, of course, had had similar or worse experiences with others! Fortunately, as the group progressed and became more of a mix of new recruits and partly treated members, we were able to overcome this resistance much more easily. Group veterans, as it were, who had made positive changes in attitudes were better able to tolerate their guilt and even confess it to other members. Moreover, there can be no doubt that confrontation is far more effective coming from peers.

\section{The treatment plan}

From the outset it was planned as an open group with a 'rolling' treatment programme, consisting of cycles of six sessions, each lasting about 90 minutes. New members can start at any time, and on their first attendance their fellow members explain the purpose 
of the meeting, the pattern of the sessions and how, although everyone has a slightly different problem, they can help each other through their own strengths and experiences. This has the additional benefit of reminding the veterans of the treatment goals and instilling the heartening notion that their past troubles can be turned to some advantage by helping others. The strict rules of group confidentiality are repeatedly endorsed, which is always welcomed and seemingly obeyed by all.

The first session is spent discussing the impact of their offences on themselves, in order to enhance their perception of deterrent factors. The risks of a long prison sentence, the victimisation of sexoffenders in prison - in terms of the hate and even beatings they will receive from other inmates, the loss of employment, the loss of friends, the disgrace of a court appearance, with the likely coverage by the media and the stigma which is then accorded to them by their local community, are all vividly brought to mind by the elicited reports of members.

The second and third sessions cover all the potential adverse consequences for the victims. This proves a difficult task, particularly when there is a high proportion of new members. Offenders may not have even understood these risks before, and certainly their guilt fuels their tendency to deny that such consequences could befall those that merely 'received their attentions'. Role play is often of advantage, helping the group see how differently children perceive their invitations and actions; for example, just how easily youngsters can be dominated into submission and naively follow their directions. Indeed, it is a sign of some success when offenders can accept that as adults they must be entirely responsible for the events.

The fourth group concentrates on the behaviour and fantasies which led them into sexual offences. Social isolation is obviously an important element, but perhaps more significant is deviant sexual fantasy material, and sometimes the collection of inappropriate pornography. Encouragingly, on occasions where direct advice has failed, positive group influences have been successful in persuading offenders to part with such prized libraries! The session hopes to give its members a better understanding of how they became offenders, so that they will be more receptive to the advice that follows in the next group.

The fifth meeting gives specific psychological help to offenders so that they can gain better control over their deviant impulses and eventually achieve more appropriate sexual fantasies and inclinations. Usually by individual examples, instruction is given in the use of covert sensitisation and orgasmic reconditioning. This is obviously difficult to do in a group situation. However, participants at least seem to go away with a resolve to try these ideas. In the corres- ponding session in the next treatment cycle, members are invited to report on their progress with these techniques. In time they are able to advise and encourage their newer fellows through describing success with such approaches. Curiously, one of the major hurdles for many is summoning up the courage to purchase appropriate pornography, to help in the development of acceptable fantasies.

In practice the most important technique is that of covert sensitisation. Individuals develop their own deterrent scenario in fantasy, be it the disgrace of a court appearance or the horror of facing an angry mob of inmates in prison, and practise it so that it can be powerfully recalled at moments of temptation. Orgasmic reconditioning, or the gradual shaping of deviant inclinations into those of a more appropriate nature, is difficult to apply from the general to the specific. Also it is best embarked upon once skill has been acquired in covert sensitisation so that masturbation to unacceptable ideas can be limited. But, of course, replacement with more appropriate gratification is essential for lasting success.

Similarly important is practical advice on how to avoid situations of potential danger. Inculcating the need to be resolute and firm at the outset of any contact with potential victims is essential. All too often offenders allow themselves, say, the company of children, believing that either they will stop themselves from becoming aroused or that they will have sufficient will-power to end the contact before problems arise. Needless to say, this proves to be most unwise. Again, reports from fellow members successfully using these skills help to spur on newer recruits to try hard to follow their example.

The final session in the cycle is directed at social rehabilitation. Sex offenders are usually lacking in social skills, interests and hobbies, and the knowledge on how to begin and where to find relevant social pursuits. Developing alternative sources of gratification other than through sex, as well as having opportunities to build up their self-esteem through the successful interaction with other adults, is vital if they are to have a secure future. Sessions focus on reducing fears of social contact through role play and discussion. Moreover, advice is given on appropriate behaviour in these situations, including the basics of how to initiate conversation and maintain the attention of others.

\section{Later hurdles}

One of the most exasperating therapeutic pitfalls is when offenders who have been attending regularly and seemingly doing well while awaiting their court appearance are then given, despite favourable reports, a prison sentence. It is even more disheartening when many of these sentences are very short and do not seem to be serving any particularly useful 
function, nor is there significant public protection in an incarceration lasting just a few months. However, some do receive substantial terms of imprisonment and this is often expected, even by the defendants themselves. Although it is still relatively early days for the group, some of those who served prison sentences have on release returned to the group, most voluntarily, some as an implicit condition of their parole.

We did expect that a number awaiting court appearances would be full of good intentions and enthusiastically sport goals of reform, only to revert once they had escaped a spell in custody! In fact, such individuals were few, and seemed more likely to be young or married. Fortunately, the group proved effective in enhancing motivation, and indifference usually changed to commitment, although sometimes under the hesitant guise of 'wanting to help their fellow offenders'!

It had been a fear of ours that bringing together recidivist sex offenders might be a cause for scandal. Perhaps, under our official auspices, some offenders could form a 'vice ring', with the exchange of undesirable pornography, giving each other erotic accounts of their exploits, or even worse the exchange of contacts. We were therefore suspicious of any subgroups forming or 'social mixing' at other times between members. Vigilant as we were, in quickly dispersing members after groups, and ensuring that we arrived early so as to supervise them as they gathered, which in fact was a useful opportunity to pick up on gossip and relevant news, some still had contact with one another outside of the group sessions..Fortunately, this seemed to be only passing in nature. Similarly, there did not appear to be any corrupting influences between the recidivists and the younger first-time offenders. However, one certainly has to remain on guard against these adverse events and closely consult receptionists and others who might witness signs of possible concern.

Another worrying problem, and one which is impossible to prevent completely, is the attainment of vicarious gratification through the group's official work. For example, when a member recounts his offence, especially when in graphic detail, others attend with interest and, it has been suspected, in a state of sexual arousal in the occasional individual. Efforts obviously have to be made to limit descriptions to a clinical account of events and emphasise the horror as seen from the victim's perspective, and at the same time play down any erotic connotations. Nonetheless, there may still be scope for some using the material to enhance their pre-existing deviant sexual fantasies. However, the fact that nearly all attend regularly and not just for these potentially arousing sessions must indicate a general high level of commitment to reform, which in turn makes it unlikely that the programme will be abused.

Lastly, some inevitably do become dependent on the group and repeatedly attend beyond two or three treatment cycles. We felt that these persons had benefited, with positive changes in their attitudes and behaviour. However, they still express a wish to continue coming. When we have asserted that it was time they left, to allow others a similar opportunity, they have always obeyed, but with obvious disappointment. Unfortunately we suspect that some of these men do need ongoing help and will be at risk of regressing and re-offending. Perhaps these offenders should be 'weaned off' the group. This could be achieved by intermittent group attendance, or less disruptively by separate and individual out-patient appointments. Not having given this much forethought, we merely told such attenders to contact us again if they had further problems. Some have done so, and a few have re-offended.

\section{The rewards}

All the advantages of group therapy over individual work clearly apply. In particular, sharing the stigma of their offences and easing fears of judgement help to minimise any obstructive excuses that 'you don't know what it is like' and resentments towards the rest of society for not having their problems! Learning and applying to themselves the solutions of others' problems, hearing their mistakes echoed by other members - both in terms of past and present behaviour, understanding through this the association of precipitants, hazards, deterrents and the potential adverse consequences for victims, are all benefits of this group work.

For example, on one occasion the group could not accept that sexual acts with young boys would cause them lasting harm, and to support this a recidivist paedophile proclaimed that he should know, because as a youngster he had been a 'rent boy' (a boy prostitute). But when questioned on how he had fallen into such a career, actually oblivious to the irony of own story or his own corrupting influence on his victims, he described being rewarded with 50 pence for letting a man fondle him and thought to himself - this is easy money! He was soon caught up in escalation of sexual exploits with men for financial gain. As a result he spent his teens exclusively involved in homosexual circles. Now in his 40 s, in the absence of any enduring relations with partners near his own age, he is still attracted to boys to fulfill his promiscuous tendencies. The group were then able to see that, despite how harmless it may seem to them, children could be led into behaviour and corruption that would prejudice their sexual development.

As mentioned previously, in a well-functioning group of like offenders, it is extremely difficult for them to deceive one another by excuses or other defences. Similarly, attenders are not just accountable to one therapist, as they would be in individual 
treatment, but have to meet the expectations of the whole group. This proves to be a powerful sanction; on occasions achieving dramatic changes. Nor is it merely a punitive force. It can also be a source of sincere praise from peers, as a reward for even minor changes, as they will appreciate the enormous efforts needed to overcome social inhibitions and breaks with easy excuses. In much the same way, members can support one another to maintain their resolution to avoid further offending, and it could be argued that this is sufficient justification for allowing a long-term supportive role.

\section{Ideas for the future}

Having devised the group to be a short-term treatment facility, we were not attentive enough to the needs of a sub-group of older, socially unskilled and isolated men who seem to value ongoing support in their lives. Perhaps this needs to take place over years while, it is hoped, they slowly move in the right direction. These latter individuals could be catered for in a second group, meeting less frequently, and, as it should be more stable, it might be managed by one therapist.

Without question, we have a duty to evaluate the benefits, successes and failures of our treatment programme. Ideally, we also need to compare its efficacy with the other approaches conducted elsewhere. We are in the process of attempting to measure our results, but are only too aware that such research requires a great deal of extra resources and commitment which is difficult for most workers to give. Yet, until firm evidence is to hand, we could either be wasting our time in providing this service or, alternatively, should be arguing for others to provide similar treatment facilities.

In any case, whatever the value, we have all enjoyed working on the project and can wholeheartedly recommend it as a challenging, exciting and rewarding experience.

\section{Acknowledgements}

We wish to thank all those who referred cases, our secretarial staff for their help, Dr Angus Campbell for his support and encouragement, and all the staff at the Minshull Street Probation Office for putting up with us!

\section{References}

${ }^{1}$ Mickow, G. \& Benson, M. (1973) Group therapy for sex offenders. Social Work (New York), 18, 98-100.

${ }^{2}$ SHAw, R. (1978) The persistent sexual offender-control and rehabilitation (a follow-up). Probation Journal, 25, 61-63.

${ }^{3}$ HoBBs, M. (1980) Group therapy with sexual offenders. Australian Journal of Clinical Hypnotherapy, 1, 105111.

\title{
The management of potentially dangerous patients in the community
}

\author{
Enda Dooley, Senior Registrar in Forensic Psychiatry, The Maudsley Hospital, London \\ SE5 (formerly Senior Registrar in Psychiatry, Broadmoor Hospital, Crowthorne, \\ Berks.)
}

With the accelerating drive towards the running down of large psychiatric hospitals and the trend towards the care and management of psychiatrically ill people in the community, it is inevitable that a small proportion of these people will be unable to cope with this change. Some patients may have a long history of violent behaviour which has been coped with in hospital. Others may have been able to cope within the 'asylum' environment but, when placed in a community which is little better able to cope with them than they are with it, regress to violent behaviour when faced with unaccustomed stress.
In attempting to care for these patients in the community, it should be borne in mind that not only are they themselves more vulnerable, but those who are expected to provide care, e.g. families, community nurses, hostel staff, GPs, social workers, etc., are placed in a more demanding situation. At a time when increasingly difficult patients are being moved to the community, staff service resources are being cut down. This increases the anxiety of those who are expected to provide this care.

It is important to bear in mind that we live in a society which is increasingly violent. The majority of 